\title{
PREMIO NUEVA CULTURA DEL TERRITORIO, MODALIDAD DE GESTIÓN Presentación del Observatorio del Paisaje de Cataluña
}

Madrid, 30 de mayo de 2019

JOAN NOGUÉ

Universitat de Girona

Señor Presidente de la Asociación Española de Geografía

Señor Presidente del Colegio de Geógrafos de España

Señoras y señores, amigas y amigos

Los impulsores del Premio Nueva Cultura del Territorio me han pedido que presente a uno de los premiados de este año, al Observatorio del Paisaje de Cataluña (OPC). Les agradezco muchísimo su amabilidad, su generosidad, el detalle que han tenido conmigo. Les confieso que su propuesta me hizo tanta ilusión como respeto: ilusión, porque el OPC es como un hijo para mí; respeto, porque no es nada fácil tomar una mínima distancia (para intentar ser lo más objetivo posible) de algo y de alguien tan cercano a ti.

Todo empezó entre el año 2000 y el 2004. España acababa de entrar en el euro, llegaban inversiones por doquier, había prisa en regularizar el dinero negro, el sector inmobiliario se mostraba como uno de los más rentables y el territorio -y su rostro, el paisaje- se transformaba a marchas forzadas, con mucho frenesí y poca sensibilidad, algo muy propio de todo nuevo rico. Empezaron a dispararse algunas alarmas, no solo en España, sino en buena parte de Europa, con académicos e intelectuales de la talla de un George Steiner alertando del riesgo de homogeneización y banalización de muchos paisajes europeos. De ahí la aprobación, en el año 2000, del Convenio Europeo del Paisaje (CEP), un hito, un referente aún hoy, como bien sabe Florencio Zoido, que hoy nos acompaña. Cataluña parti- 
cipaba también de esta especie de jolgorio colectivo, de esta fiesta irresponsable, entre otras razones porque nadie sabía (entonces) quién la iba a pagar. Eso lo hemos sabido -y padecido- más tarde.

Algunas personas, preocupadas ante este panorama y angustiadas al ver cómo se degradaban nuestros paisajes sin que pareciese que a nadie le importase demasiado, empezamos a movilizarnos desde la base, desde la sociedad civil. Había que hacer algo, había que crear algo que aglutinase a personas e instituciones preocupadas por lo que estaba sucediendo y que tuviese como eje vertebrador al paisaje.

¿Pero qué? ¿Una asociación? ¿Una ONG? ¿Una fundación privada? En noviembre de 2003 lo tuvimos claro: un consorcio. Acababa de ganar las elecciones el primer tripartito de izquierdas, liderado por Pasqual Maragall e integrado por políticos muy sensibles a nuestro objetivo, como el geógrafo Oriol Nel.lo o el historiador Joaquim Nadal. Un consorcio público permitiría reunir en una misma institución a las entidades y asociaciones que habían sido capaces de poner el tema sobre la mesa y, a la vez, a la administración pública (en todos sus niveles), a las universidades y a los agentes económicos y sociales con más incidencia en la transformación del paisaje. Y así es como aparece recogido en la Ley de protección, gestión y ordenación del paisaje de 8 de junio de 2005, siete meses más tarde de la creación del propio Observatorio. No es un detalle menor el hecho de que el ordenamiento jurídico recogiera y reconociera una iniciativa surgida en realidad de la propia sociedad civil, algo poco habitual, entonces y ahora.

Esta estructura tan híbrida y transversal es clave a la hora de explicar por qué se han hecho tantas cosas, en tan poco tiempo y con tan pocos recursos. La corresponsabilidad, las sinergias, las complicidades compartidas convirtieron muy pronto al OPC en un terreno de todos y de nadie a la vez, con una línea de trabajo muy clara y consensuada, con un nivel de autonomía muy poco habitual en entidades con presencia de la administración, y con una gran flexibilidad y capacidad de reacción y de adaptación a los nuevos temas y a los nuevos tiempos.

Esta libertad de acción, solo condicionada por los recursos existentes, ha sido y es un elemento clave, porque ha garantizado que los planes de trabajo anuales, aprobados por un consejo rector de amplísima composición en cuanto a perfiles y sensibilidades, se hayan pensado atendiendo solamente a su interés para el bien común y para el avance del conocimiento, la educación y la concienciación social en lo relativo al paisaje.

El OPC es un centro de acción y de reflexión en temas de paisaje. Forma, asesora, educa y sensibiliza, pero también investiga, innova y crea conocimiento, so- 
bre todo de carácter metodológico. Y lo hace desde Cataluña, desde este pequeño rincón del noreste peninsular, pero abriéndose al mundo. Desde el primer día su página web y sus boletines digitales se han editado y difundido a todo el mundo en ediciones paralelas en catalán, español e inglés (también en francés en algunos momentos y supuestos); participa en organismos e iniciativas internacionales de todo tipo; asesora sobre cómo aplicar la filosofía que emana del CEP a lo largo de todo el continente europeo; y se implica en la generación de nuevas ideas e instrumentos vinculados a la gestión del paisaje que mejoren la calidad de vida y el bienestar social en entornos culturales muy diversos y en contextos geopolíticos nada fáciles: de América Latina al Magreb, pasando por Líbano, Chipre y otros países del Mediterráneo oriental. Lo más relevante de esta apertura al mundo no es que le haya convertido en un referente internacional ni que, gracias a la misma, haya recibido reconocimientos de todo tipo. Lo más relevante, lo más importante, es que ha aprendido y se ha enriquecido muchísimo; se ha empapado, se ha impregnado de otras visiones y sensibilidades. Y ello ha redundado en una mejora de la calidad del trabajo realizado al volver a casa. El OPC es, claramente, glo-cal, pero no en teoría, no en sus principios, sino en el día a día.

El Premio Nueva Cultura del Territorio tiene como finalidad fomentar una nueva cultura del territorio mediante el reconocimiento de personas, entidades e instituciones que hayan contribuido de forma relevante al impulso de una ordenación y gestión del territorio fundamentada en valores de sostenibilidad ambiental, eficiencia económica y equidad social, en línea

con la filosofía que se recoge en el Manifiesto por una Nueva Cultura del Territorio. Tengo el enorme privilegio de haber podido comprobar que así es en el caso de la labor realizada por el OPC. Estos son sus valores, en efecto. Pero si estos valores se han mantenido intactos a lo largo de sus 15 años de existencia y si a ellos se han añadido muchos más, ha sido gracias a un equipo humano de una enorme valía; un reducidísimo equipo interdisciplinario que ha vivido esta aventura con pasión, que ha trabajo con ahínco y, sobre todo, dando muestras de una generosidad poco habitual. Un equipo dirigido desde hace dos años por Pere Sala, una persona extraordinariamente lúcida y sensible que ahora van a tener ocasión de escuchar. Les aseguro que, sin él, el OPC no sería lo que es.

Gracias, Pere. Gracias a todo el equipo, hoy presente en esta sala casi al completo, por la ingente labor que estáis desarrollando con unos recursos ínfimos, absolutamente insuficientes. Gracias por haber contribuido a que el paisaje haya entrado (para quedarse) en la agenda política y en las políticas territoriales.

El paisaje no tiene solo una dimensión subjetiva e individual; es, sobre todo, un proyecto y un bien común, con unos valores objetivables y gestionables, por 
más que los experimentemos y disfrutemos de manera individual. Para el buen 'governo del paesaggio', como dirían nuestros colegas italianos, se precisa de un armónico equilibrio entre percepción individual y acción colectiva, siempre desde la consideración de que todo paisaje es, en última instancia, una construcción social, algo que el OPC ha tenido siempre muy claro.

Muchas gracias por su atención. 